\title{
EXTERNAL FAILURE OF DEEP MIXING COLUMNS REINFORCED BY A SHALLOW LAYER BENEATH AN EMBANKMENT
}

\author{
Binh NGUYEN ${ }^{1}$, Tomohide TAKEYAMA ${ }^{2}$ and Masaki KITAZUME ${ }^{3}$ \\ ${ }^{1} \mathrm{Ph} . \mathrm{D}$. candidate, Dept. of Civil Eng., Tokyo Institute of Technology \\ (2-12-1, Ookayama, Meguro-ku, Tokyo 152-8552, Japan) \\ E-mail: nguyen.b.ac@m.titech.ac.jp; nttbinh86@gmail.com \\ ${ }^{2}$ Member of JSCE, Associate Professor, Dept. of Civil Eng., Kobe University \\ (1-1 Rokkoudai, Nada-ku, Kobe 657-8501, Japan) \\ E-mail: takeyama@ people.kobe-u.ac.jp \\ ${ }^{3}$ Member of JSCE, Professor, Dept. of Civil Eng., Tokyo Institute of Technology \\ (2-12-1, Ookayama, Meguro-ku, Tokyo 152-8552, Japan) \\ E-mail: kitazume.m.aa@m.titech.ac.jp
}

\begin{abstract}
Deep mixing columns have been widely used to support embankments constructed on soft ground condition. A layer of shallow mixing is proposed to fix and reinforce these columns to increase their stability and the loading capacity of columned improved area. This study focuses on the external failure pattern of deep mixing columns reinforced by a stabilized shallow layer where the high strength columns fail due to large deformation without any failure inside the columns. Centrifuge model tests were carried out to investigate the effect of shallow layer on reducing embankment displacement and on the failure mechanism of deep mixing columns. High and low strength bottom layers where the columns deposit on were also considered. Acrylic pipes were used as deep mixing columns in the centrifuge tests to avoid unexpected internal failure. As a result, the tilting and sliding failures were observed as two main failure patterns of the improved ground in term of external stability. The tilting failure was found as the main failure pattern of the isolated columns. The stabilized shallow layer can significantly reduce the tilting displacement of improved area while the sliding displacement is considerably influenced by the bottom layer's strength. The effect of the shallow layer on the embankment displacement and the stability of the columned improved ground are also discussed in this study.
\end{abstract}

Key Words: centrifuge modeling, embankment, deep mixing, shallow mixing

\section{INTRODUCTION}

Cement or lime and soil mixing technique was first used in Japan and Nordic countries in the 1970s. The technique has been used to improve soft soil by improving its mechanical properties including strength and consolidation characteristics ${ }^{1}$. On the one hand, a lot of researches were conducted to investigate the characteristics of stabilized soil due to various factors including types of binder, properties of soil, mixing condition and curing condition ${ }^{2}$. Additionally, many studies focused on the applicability of in-situ mixing technique such as supporting embankment and port facilities as well as working as the foundation of building and factory ${ }^{1)}$. In terms of embankment supporting, column-type improvement is taken into ac- count for huge applications ${ }^{3), 4), 5), ~ 6) . ~ D u e ~ t o ~ e m b a n k-~}$ ment loading, the deep mixing columns tend to fail either by the external failure ${ }^{7)}$, ${ }^{8}$ where the failure happens due to great displacement of the high strength columns without any damage inside the columns or the internal failure, ${ }^{8), 9), 10), 11)}$ which is the failure that happens inside the columns due to its lowstrength material. Because the deep mixing columns do not fail simultaneously but one by one at different times ${ }^{7), 9)}$, the strength and stiffness of all the columns cannot be mobilized simultaneously. By using a stabilized shallow mixing layer to fix the top of deep mixing columns, the isolated columns are expected to work simultaneously as a group. A combined technology of the shallow stabilization and floating-type cement stabilized columns was applied to reduce the settlement of a high embankment on a soft ground ${ }^{12)}$. 
Another research on the effect of surface improvement layer on the internal stability of group columntype deep mixing under embankment load was also reported ${ }^{13)}$. In addition, a field test in which a soil cement stabilized slab was used to fix and reinforce the deep mixing columns was conducted to study the settlement of an embankment. The embankment supported by the combined structure including deep mixing columns and stabilized slab is a part of the Ariake Sea Coast Road project, which is currently under construction in Fukuoka, Japan ${ }^{14)}$. However, the failure pattern of the combined structure, including the shallow layer and deep mixing columns, has not been well studied.

On the other hand, physical modelling has been widely used recently to study geotechnical problems. The centrifuge model test, which can simulate the stresses and strains of the real prototype structure by a scale model under high gravity condition, is one of the most popular physical modelling methods used by geotechnical specialists. The applicability of the physical modelling on the topic of using the deep mixing columns to support embankment was recently reported by many researchers ${ }^{15), 16), 17), 18)}$.

In this study, the centrifuge model test was also used to investigate the failure pattern of deep mixing columns supporting embankment when a shallow layer was used to fix and to reinforce the isolated columns. The scope of this research is to focus on the external stability of the deep mixing columns reinforced by the shallow layer. In order to avoid unexpected internal failure taking place in the deep mixing columns, the acrylic piles and acrylic plate were used to simulate the deep mixing columns and the shallow layer, respectively. The process of constructing the embankment during centrifuge tests was carried out by using an in-flight sand hopper ${ }^{19}$. Four centrifuge model tests were done to investigate the effect of stabilized shallow layer and the bottom layer's strength beneath the columns on the failure pattern of the improved area, including the deep mixing columns and the shallow layer. The effects of the stabilized shallow layer on the embankment displacement and the stability of the improved ground are also discussed in this study.

\section{APPARATUS AND EQUIPMENT}

In this study, centrifuge model tests were conducted by the Mark III geotechnical centrifuge at Tokyo Institute of Technology ${ }^{20)}$ (Fig. 1). Detailed specifications of the centrifuge are shown in Table 1. A rectangular model container was used for the experiment where the inside dimension of the container is $150 \mathrm{~mm} \times 500 \mathrm{~mm}$ where the depth is $362 \mathrm{~mm}$.

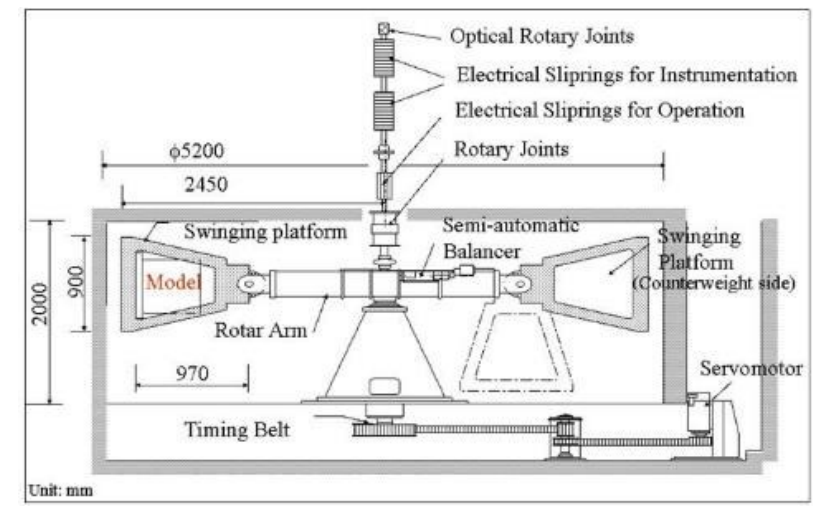

Fig. 1 Mark III centrifuge at Tokyo Institute of Technology.

Table 1 Mark III centrifuge specifications ${ }^{20)}$.

\begin{tabular}{l||ll}
\hline \multirow{2}{*}{ Radius } & Platform radius & $2.32 \mathrm{~m}$ \\
\cline { 2 - 3 } & Effective radius & $2.1 \mathrm{~m}$ \\
\hline \multirow{2}{*}{$\begin{array}{l}\text { Platform } \\
\text { dimensions }\end{array}$} & Width & $0.9 \mathrm{~m}$ \\
\cline { 2 - 3 } & Depth & $0.9 \mathrm{~m}$ \\
\cline { 2 - 3 } & Maximum height & $0.97 \mathrm{~m}$ \\
\hline \multirow{4}{*}{ Capacity } & Maximum payload & $50 \mathrm{~g} . t o n$ \\
\cline { 2 - 3 } & $\begin{array}{l}\text { Maximum number of } \\
\text { rotation }\end{array}$ & $300 \mathrm{rpm}$ \\
\cline { 2 - 3 } & Maximum payload at $80 \mathrm{G}$ & $600 \mathrm{~kg}$ \\
\cline { 2 - 3 } & Maximum acceleration & $100 \mathrm{G}$ \\
\hline
\end{tabular}

Three sides of the container are made by steel while the front side is made of acrylic plastic for visual observation during the experiments. During the centrifuge tests, an in-flight sand hopper was used to simulate embankment construction with the sand raining technique. The technique first introduced by Beasley in $1976^{19)}$ has been used recently in geotechnical centrifuge modeling tests 7 ), 9), 16), 21), 22). The cubic-shape sand hopper box has inside dimension of $200 \mathrm{~mm} \times 200 \mathrm{~mm}$ and $200 \mathrm{~mm}$ deep. The hopper is divided into 10 cells in order to adjust the thickness of embankment slope. To be more detailed, the thinnest thickness is about $25 \mathrm{~mm}$ at the toe side of embankment where the thickest one is about $145 \mathrm{~mm}$ at the center of the embankment. In other cells, the thickness was increased gradually from the toe side to the center of the embankment.

\section{MODEL GROUND}

\section{(1) Test condition}

The detailed model ground condition used in the centrifuge model tests is shown in Fig. 2a in a model scale dimension. The clay layer was $200 \mathrm{~mm}$ thick while the lower stiff sand layer was $30 \mathrm{~mm}$ thick in model scale. The water table was kept constant at the clay layer surface during the tests. On the improved area, as can be seen in Fig. 2c, 12 columns $20 \mathrm{~mm}$ in 
diameter were arranged as a square pattern at the toe side of the embankment for the purpose of improving the embankment's slope. The improvement area ratio, which is defined as the ratio between the sectional areas of the deep mixing columns to that of the total improved area, is $22.3 \%$ and is kept constant for all centrifuge model tests. The shallow layer was used to fix all the isolated columns at their tops as can be seen from the figure. The thickness and width of the shallow layer were fixed at 40 and $120 \mathrm{~mm}$, respectively, which were also kept the same for all tests. Centrifuge model tests were conducted under a $50 \mathrm{~g}$ centrifugal environment with and without reinforcement by stabilized shallow layer for two bottom conditions,

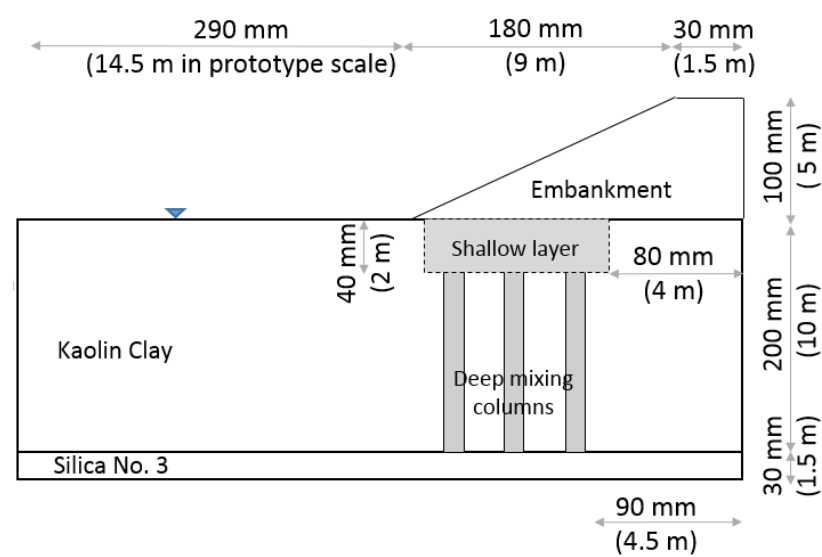

(a) Model ground - Fixed-type columns

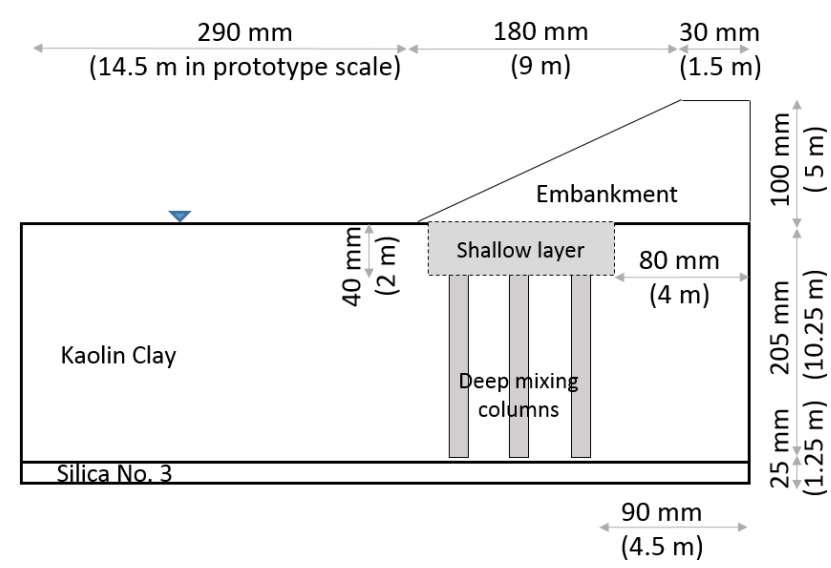

(b) Model ground - Floating-type columns

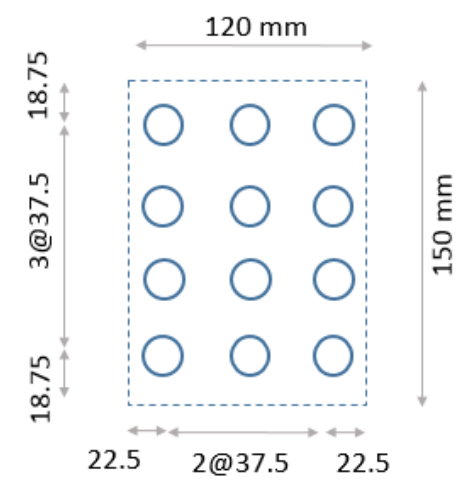

(c) Plain view of columns' pattern

Fig. 2 Soil condition of centrifuge model tests (model scale). including fixed-type and floating-type columns where the detailed test cases are later shown in Table 6. In the fixed type, the columns stood on a stiff sand layer at their bottom which was used to simulate the high-strength bottom condition (Fig. 2a). In the floating type with a thin clay layer $(5 \mathrm{~mm}$ thick in scale dimension) underneath the columns, the low-strength bottom was considered as can be seen in Fig. 2b. An embankment was constructed at the right side of the model ground during the centrifuge test as shown in the figure.

\section{(2) Materials \\ a) Kaolin}

The detailed physical properties of Kaolin clay used in this study to simulate the soft ground layer are shown in Table 2.

\section{b) Silica No. 3}

The drainage and stiff layer, where the soft ground layer deposits, was made by Silica No. 3. The detailed physical properties of this Silica No. 3 are presented in Table 3. In the model test, the density and unit weight of this sand layer were about $50 \%$ and $14.2 \mathrm{kN} / \mathrm{m}^{3}$ while its friction angle was confirmed at about 41 degrees.

\section{c) Zircon sand}

Zircon sand was used commonly at our geotechnical group at Tokyo Institute of Technology as the method to increase the surcharge load due to its high specific gravity as shown in Table $\mathbf{4}$ where the unit weight was confirmed at about $33 \mathrm{kN} / \mathrm{m}^{3}$ in all centrifuge model tests.

Table 2 Physical properties of Kaolin clay ${ }^{20)}$.

\begin{tabular}{lc}
\hline Specific Gravity, $G_{\mathrm{s}}$ & 2.61 \\
\hline Liquid Limit, $W_{\mathrm{L}}(\%)$ & 77.5 \\
\hline Plastic Limit, $W_{\mathrm{P}}(\%)$ & 30.3 \\
\hline Plastic Index, $I_{\mathrm{P}}$ & 47.2 \\
\hline Compression Index, $C_{\mathrm{c}}$ & 0.56 \\
\hline Swelling Index, $C_{\mathrm{s}}$ & 0.10 \\
\hline$k_{0}$ & 0.6 \\
\hline$c_{\mathrm{u}} / p$ & 0.24 \\
\hline
\end{tabular}

Table 3 Physical properties of Silica No. $3^{17}$.

\begin{tabular}{ll}
\hline Specific Gravity, $G_{\mathrm{s}}$ & 2.65 \\
\hline$D_{50}(\mathrm{~mm})$ & 1.4 \\
\hline Uniformity coefficient, $U_{\mathrm{c}}$ & 1.27 \\
\hline Maximum void ratio, $e_{\max }$ & 1.01 \\
\hline Minimum void ratio, $e_{\min }$ & 0.7 \\
\hline Coefficient of permeability, $k(\mathrm{~cm} / \mathrm{s})$ & $3.82 \times 10^{-2}$ \\
\hline
\end{tabular}


Table 4 Physical properties of Zircon sand ${ }^{17)}$.

\begin{tabular}{ll}
\hline Specific Gravity, $G_{\mathrm{s}}$ & 4.66 \\
\hline Internal friction angle (degree) & $34^{\circ}$ \\
\hline
\end{tabular}

Table 5 Comparison on moment stiffness.

\begin{tabular}{|c|c|c|}
\hline & Acrylic pile & $\begin{array}{c}\text { Deep mixing } \\
\text { column }\end{array}$ \\
\hline \multirow{2}{*}{ Diameter (m) } & inner & \\
\hline & 0.017 & 0.02 \\
\hline $\begin{array}{l}\text { Elastic modulus } \\
E(\mathrm{GPa})\end{array}$ & $2.8 \sim 4.2$ & $0.5 \sim 3.0$ \\
\hline $\begin{array}{l}\text { Area moment of } \\
\text { inertia } I\left(\mathrm{~m}^{4}\right)\end{array}$ & $3.75 \times 10^{-9}$ & $7.85 \times 10^{-9}$ \\
\hline $\begin{array}{l}\text { Moment of stiff- } \\
\text { ness } E I\left(\mathrm{kNm}^{2}\right)\end{array}$ & $0.011 \sim 0.016$ & $0.004 \sim 0.024$ \\
\hline
\end{tabular}

\section{d) Acrylic}

Because this research will focus on studying the external failure mechanism of the deep mixing columns reinforced by the shallow layer, the model columns with $20 \mathrm{~mm}$ in outer diameter were made by acrylic pipe in order to avoid any internal failure during the centrifuge tests ${ }^{7}$. To adjust the unit weight of columns, which is assumed to be the same as that of the surrounding clay, an iron rod with $6 \mathrm{~mm}$ diameter was inserted inside the acrylic pipe and hot paraffin was poured into the pipe. A comparison on the moment of stiffness between the real high-strength deep mixing columns and the model acrylic pipe is shown in Table 5.

The material elastic modulus of acrylic plastic was confirmed to be around $2.8 \mathrm{GPa}$ to $4.2 \mathrm{GPa}^{23)}$ while many studies reported that the elastic modulus of the high strength deep mixing was around 0.5 GPa to 3.0 $\mathrm{GPa}^{1)}$. A simple calculation in the Table shows that the acrylic pipe can be used to simulate the deep mixing in terms of high-strength material where the range for moment of stiffness of the deep mixing columns includes that range for acrylic pipe with the same diameter.

Sand blasting technique was also applied on the column surface to make the rough surface for simulating the interface interaction between deep mixing columns and surrounding Kaolin clay. Similarly, shallow layer was made by acrylic plate adjusted by a thin aluminum plate (Fig. 3). In this study, the connection between the deep mixing columns and the shallow layer was assumed as rigid connection to observe the external failure pattern of the improved area. Hence, screws were used to fix the shallow layer to the columns at the top as shown in the figure.

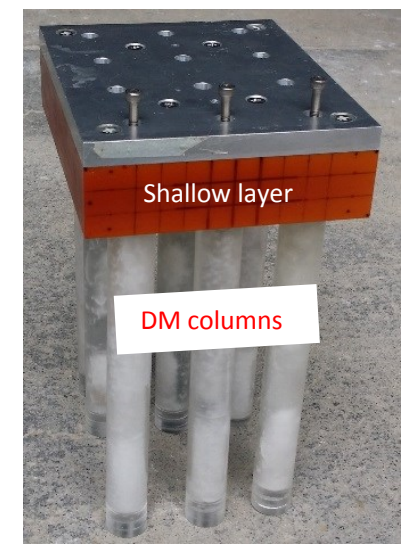

Fig. 3 Deep mixing and shallow layer.

\section{(3) Preparation and test procedure}

In the model preparation, Silica No. 3 was first poured into the model container to make a drainage and stiff layer at the bottom. Kaolin clay slurry was made by mixing Kaolin powder with $100 \%$ water content for one hour in de-air condition by using the vacuum pump. The water content was calculated based on the dry weight of Kaolin powder. The Kaolin clay slurry was then poured on the stiff silica layer, and one-dimensionally consolidated by using an air-compression cylinder under a consolidating pressure of $200 \mathrm{kPa}$ to achieve a targeted strength of the soft ground. After 10 days of consolidating, the targeted thickness of Kaolin clay was achieved at 200 $\mathrm{mm}$.

The uniformity of the Kaolin clay after consolidation was confirmed by investigating the water content as well as shear strength along the depth. Results for the water content and the shear strength, which were obtained by vane shear test are shown in Fig. 4a and 4b respectively. Particularly, Figure $4 \mathbf{a}$ confirms that water content of Kaolin clay is about $60 \%$ which is almost uniform along the depth of the soft ground layer. The results well agreed with the estimated water content based on laboratory tests which are also shown as broken lines in the figure. The shear strength of Kaolin clay shown in Fig. $\mathbf{4 b}$ is about 30 $\mathrm{kPa}$ for all tests and slightly increases with depth. A sample of Kaolin clay for unconfined compressive test was collected after each centrifuge test at the most left hand side of the model ground to avoid the effect of large deformation from the embankment on the unconfined compression test results. The test results are shown in Table 6 for all tests. The results of unconfined compression tests together with water content and shear strength with depth, confirm that all four model grounds share the same Kaolin clay strength properties which is almost uniform along the depth of the model ground layer. 


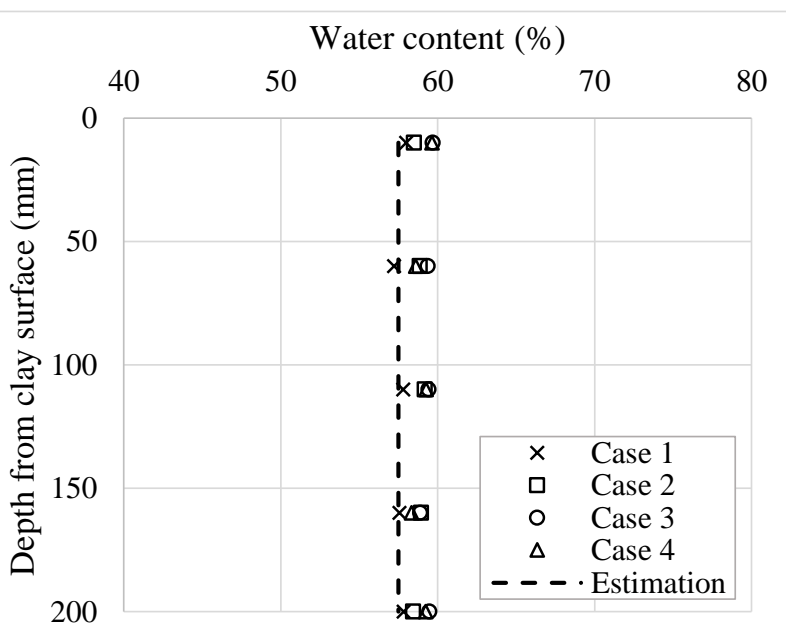

(a) Water content

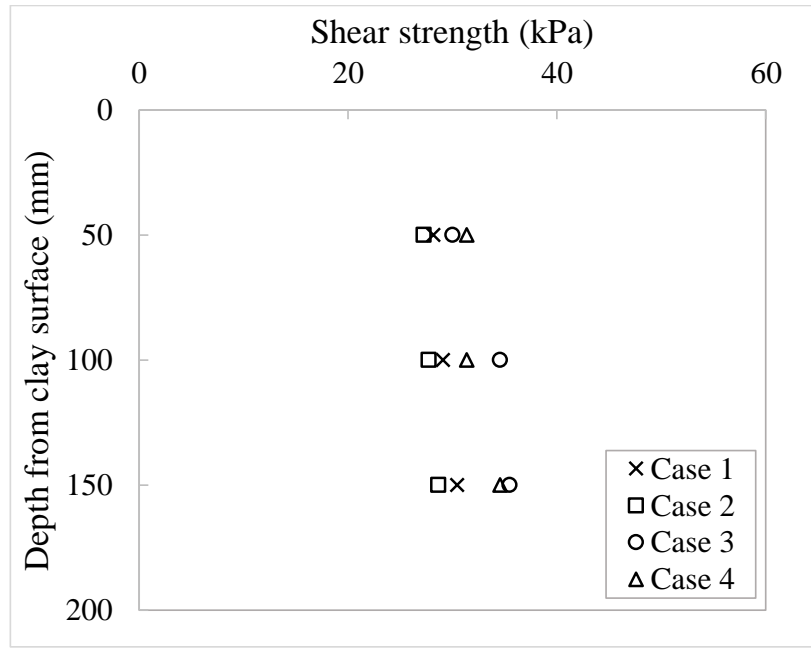

(b) Shear strength

Fig. 4 Water content and shear strength of the Kaolin clay layer.

Table 6 Unconfined compression tests on Kaolin clay for all test cases.

\begin{tabular}{lllll}
\hline Test cases & Case 1 & Case 2 & Case 3 & Case 4 \\
\hline Test conditions & $\begin{array}{l}\text { High strength bottom } \\
\text { without shallow layer }\end{array}$ & $\begin{array}{l}\text { High strength bottom } \\
\text { with shallow layer }\end{array}$ & $\begin{array}{l}\text { Low strength bottom } \\
\text { without shallow layer }\end{array}$ & $\begin{array}{l}\text { Low strength bottom } \\
\text { with shallow layer }\end{array}$ \\
\hline Abbreviation & C1-H & C2-HwS & C3-L & C3-LwS \\
\hline Unit Weight $\left(\mathrm{kN} / \mathrm{m}^{3}\right)$ & 16.3 & 16.2 & 16.0 & 16.1 \\
\hline$q_{\mathrm{u}}(\mathrm{kPa})$ & 31.1 & 37.2 & 39.3 & 36.9 \\
\hline$E_{50}(\mathrm{kPa})$ & 206.3 & 288.1 & 337.5 & 251.7 \\
\hline
\end{tabular}

Before installing the columns into the model ground, the front door of the model container was opened to attach the optical markers as can be seen in Fig. 5. The markers were set up to be used for measuring the displacement of model ground by using the particle tracking velocimetry technique (PTV $)^{24)}$. By using a large sized marker (4 $\mathrm{mm}$ in diameter) together with high quality photos taken by high speed camera, the accuracy of PTV method obtained by manual measurement was confirmed to be about \pm 0.1 pixel $( \pm 0.65 \mathrm{~mm}$ in model scale). The process of preparation will continue by installing the columns and the shallow layer. In order to set up the columns into the model clay ground, a thin-walled tube with $20 \mathrm{~mm}$ outer diameter was inserted into the clay's layer, the soil inside the tube then was removed by a tiny auger to excavate a hole for installing the model columns after withdrawing the tube. This procedure was repeated carefully to avoid great disturbance on the model ground until all 12 columns were installed. Using a guiding plate ensured the projected positions of the columns as well as the vertical straight of the columns. When using shallow layer, the Kaolin clay at shallow layer position was excavated before setting up the columns. After installing the columns, the shallow layer was fixed to the column group by screws. Two earth pressure gauges were placed at the embankment center along the embankment longitude

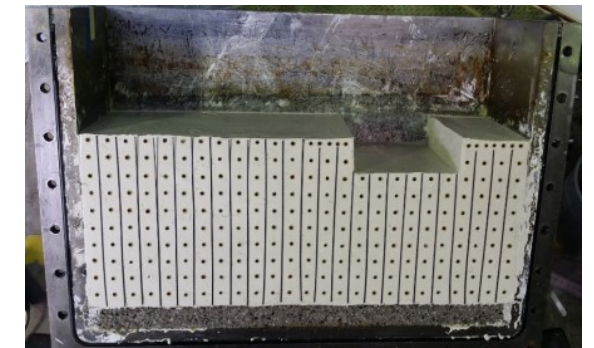

Fig. 5 Optical markers attached on the Kaolin clay layer.

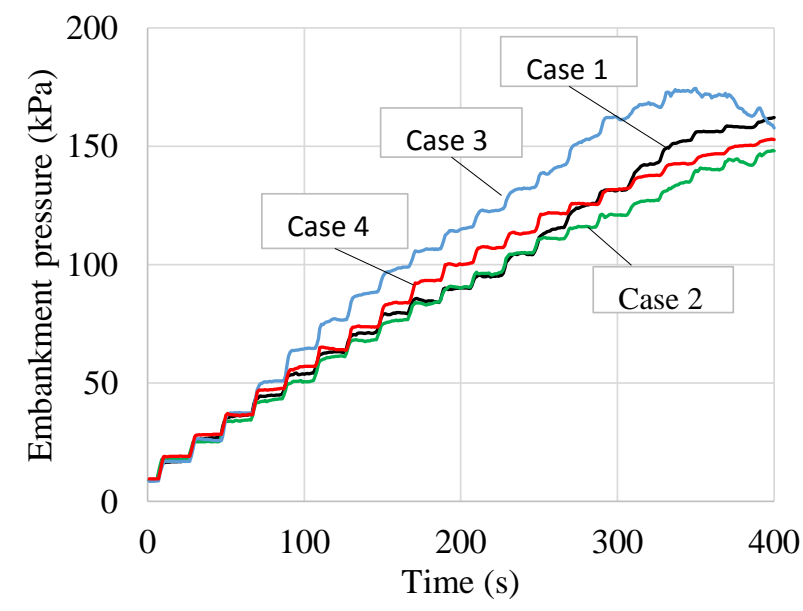

Fig. 6 Average embankment pressure during construction.

to investigate the embankment pressure during construction. 
After preparing the model ground, the sand hopper was assembled to the model container on the topright part of the container. Zircon sand was prepared into the sand hopper's cells based on the sand weight for each cell, which were obtained from the calibrating tests. The testing program was designed to observe the deformation of the model soft ground layer as well as the displacement of the improved area while constructing the embankment. The centrifuge test was finished after a total of 20 steps of embankment construction was executed at $50 \mathrm{~g}$ environment. Details of the columns' final displacement were observed by excavating the surrounding Kaolin clay to expose the improved area. Kaolin clay's sample for the unconfined compression tests was then also taken.

\section{RESULTS AND DISCUSSIONS}

\section{(1) Embankment pressure}

The average embankment pressure obtained from two earth pressure gauges under embankment for four tests is shown in Fig. 6. The loading process started at $50 \mathrm{~g}$ acceleration gradually increasing the embankment pressure as can be seen in the figure. The horizontal axis of this figure shows the loading time, while the vertical one indicates the embankment pressure. Results from the figure confirm that all centrifuge tests were conducted almost at the same loading condition. In particular, the loading condition was controlled as short-time construction for studying the undrained behavior of the model ground where the maximum embankment pressure was confirmed about $160 \mathrm{kPa}$. One step of loading was carried out within 20 seconds with 3 -second sand raining. Right after finishing 20 loading steps, the centrifuge test was stopped by reducing the $\mathrm{G}$ value to $1 \mathrm{G}$ environment in order to avoid the time effect on the deformation of the model ground.

\section{(2) Deformation of model ground}

Figure 7 shows a series of graphs on the maximum shear strain distribution at the final embankment pressure for all model tests obtained from the measured movement of visual markers. As can be seen in the figure, large strain was found at the area under and near the embankment in all four tests. In particular, the upper photos show the strain field of the model ground supported by the columns resting on a high-strength bottom layer. From the strain distribution, larger strain can be observed for the model ground with isolated columns in $\mathrm{C} 1-\mathrm{H}$ compared to that with columns reinforced by the shallow layer in C2-HwS.
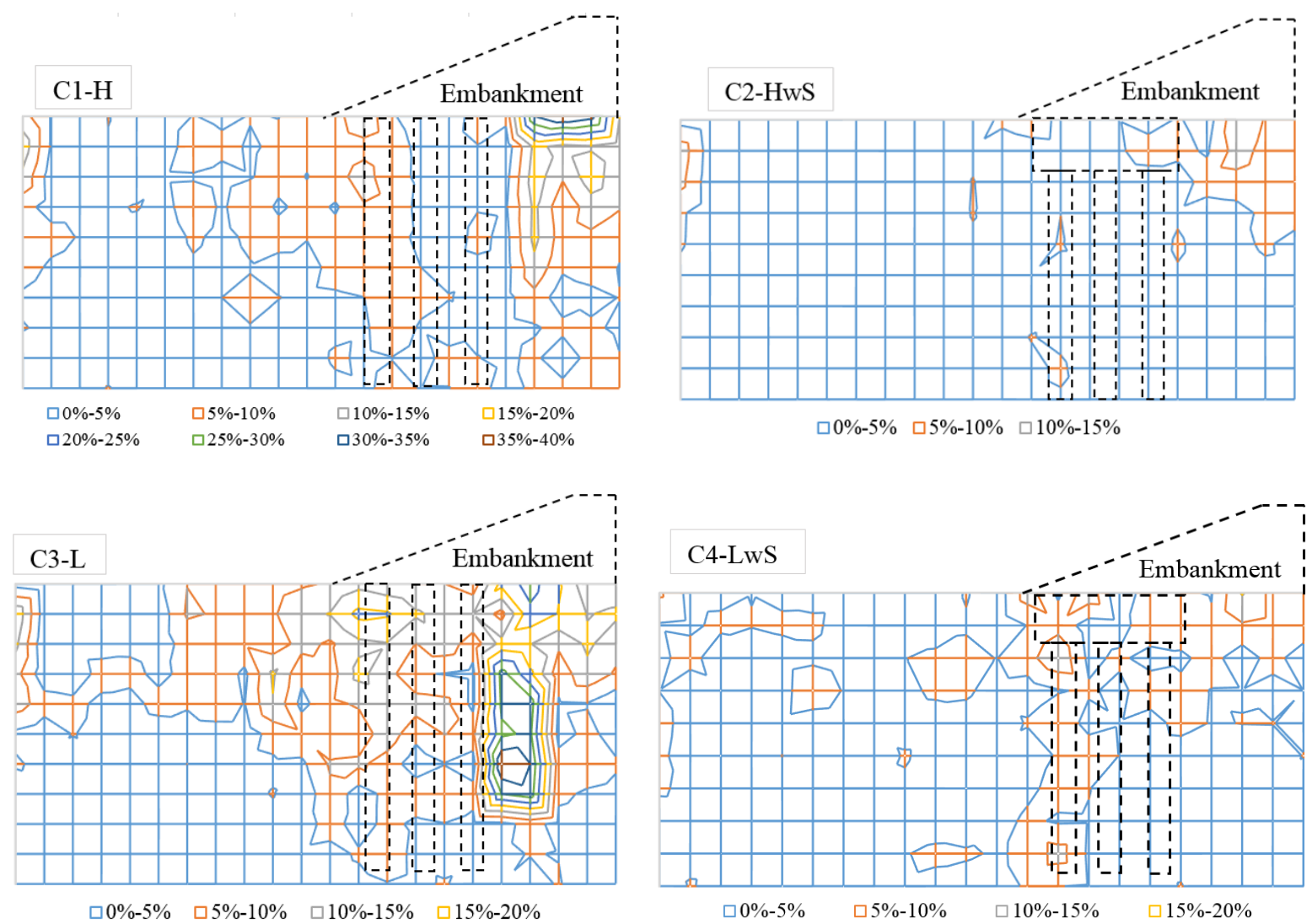

Fig. 7 Strain field of model ground at final embankment pressures. 
Similarly, the greater strain was found in the test case C3-L in comparison to that in C4-LwS for the model ground supported by the columns resting on a low strength bottom layer (lower photos). A comparison of the two supporting bottom conditions showed that for the isolated columns, large strain also occurred at the bottom of the columns in $\mathrm{C} 3-\mathrm{L}$, similar to those of $\mathrm{C} 1-\mathrm{H}$. The result confirmed a movement at the bottom part of the improved area with low strength-bottom support. With the shallow layer, the same pattern was also found in C4-LwS with larger strain in front of the columns' bottom than that in C2HwS.

\section{(3) Displacement of the embankment}

The deformation of the embankment was measured by using the PTV technique to track the movement of the optical markers. The horizontal displacements at the embankment toe and the settlement under embankment are observed and presented in Fig. 8. It should be noted that prototype scale from this section will be used for discussion. For easier understanding, the prototype dimension of the model ground is shown in Fig. 2a and $\mathbf{2 b}$ (in parentheses).

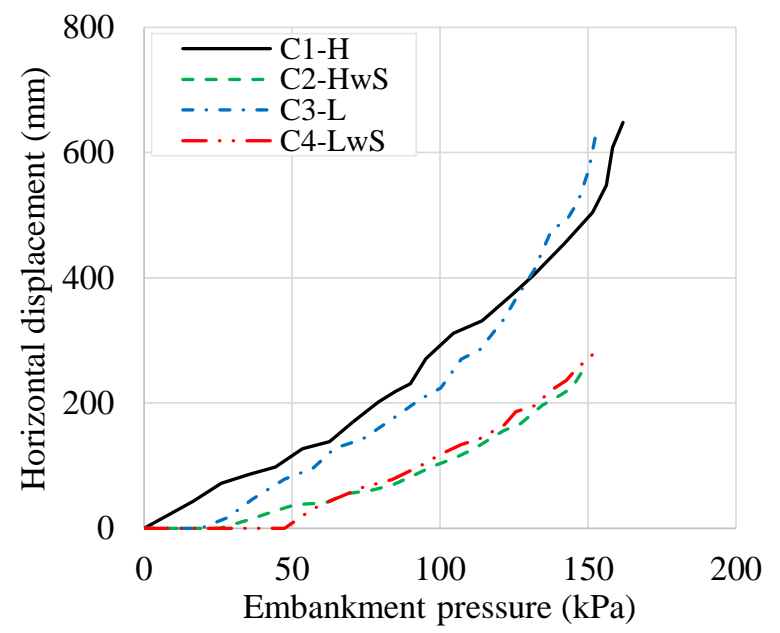

(a) Horizontal displacement at embankment toe

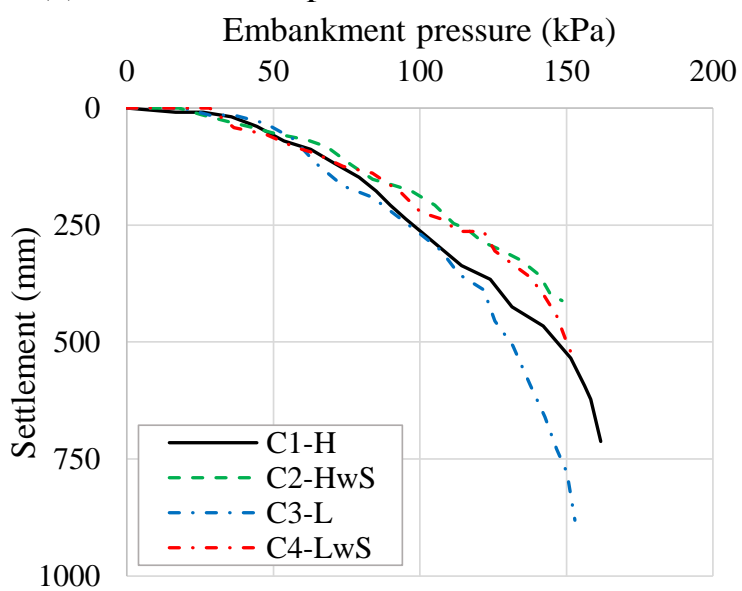

(b) Settlement under embankment

Fig. 8 Embankment displacements.
In all test cases, the horizontal displacement of embankment gradually increases with embankment pressure as shown in Fig. 8a. Smaller displacement takes place at the embankment toe in the test with the shallow layer irrespective of the bottom layer strength where the columns stand on. Furthermore, the horizontal displacement is almost the same in the case with the shallow layer for both low and high strength of the bottom layer (C2-HwS and C4-LwS). In the test without the shallow layer, compared to the case $\mathrm{C} 1-\mathrm{H}$, the columns supported by low-strength bottom in case C3-L bring a smaller displacement of embankment toe when embankment pressure is small. At greater embankment pressure level about $150 \mathrm{kPa}$, the embankment in case C3-L tends to have larger displacement than that in case $\mathrm{C} 1-\mathrm{H}$. However, the difference in horizontal displacement in both cases is not significant. Additionally, Fig. 8b indicates the settlement under embankment for all tests. When embankment pressure was less than $100 \mathrm{kPa}$, the ground settlements in all four tests almost were the same. However, by increasing embankment pressure, the embankment in case C3-L experienced the largest settlement while the embankment settlement was the least in the case of the columns resting on the high-strength layer with the shallow layer reinforcement shown in $\mathrm{C} 2-\mathrm{HwS}$.

By looking at the horizontal displacement decrement in Fig. 8a at the embankment pressure of 150 $\mathrm{kPa}$, the embankment's horizontal displacement considerably decreases when applying the shallow layer to fix the isolated columns. Specifically, the tests' results on the columns resting on the low-strength layer (C3-L and $\mathrm{C} 4-\mathrm{LwS}$ ) confirm a reduction of 50\% while that on the columns supported by high-strength bottom layer $(\mathrm{C} 1-\mathrm{H}$ and $\mathrm{C} 2-\mathrm{HwS})$ indicates about $40 \%$ of decrement in the horizontal displacement at the embankment toe.

The stability of embankment can be evaluated by the yield pressure, which is defined by the embankment pressure at a clear bending point in the loaddisplacement curve. Because the columns were used to support the embankment slope, the horizontal displacement is taken into account for evaluating the embankment pressure at yield. Hence, the yield pressure is obtained by replotting Fig. 8a in the semi-logarithmic scale and shown in Fig. 9. The embankment pressure at yield is strongly affected by the shallow layer. Specifically, the yield pressure is increased from $90 \mathrm{kPa}$ to $140 \mathrm{kPa}$ by the shallow layer, while the strength of the bottom layer beneath the improved area may have small effect on the yield pressure.

Because of the significant increase of the embankment yield pressure as well as the large decrease of the horizontal displacement of embankment when isolated columns are reinforced by the shallow layer, 
it can be said that the shallow layer gains stability of the improved ground by deep mixing columns irrespective of the bottom strength condition underneath the columns.

\section{(4) Displacements of the columns}

The displacement of columns is investigated by observing the attached markers through the front

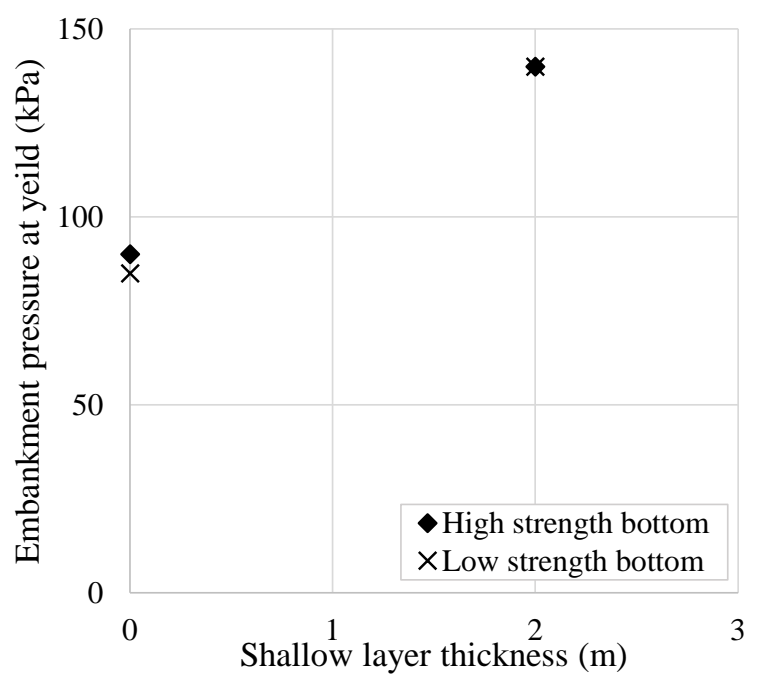

Fig. 9 Embankment pressure at yield.
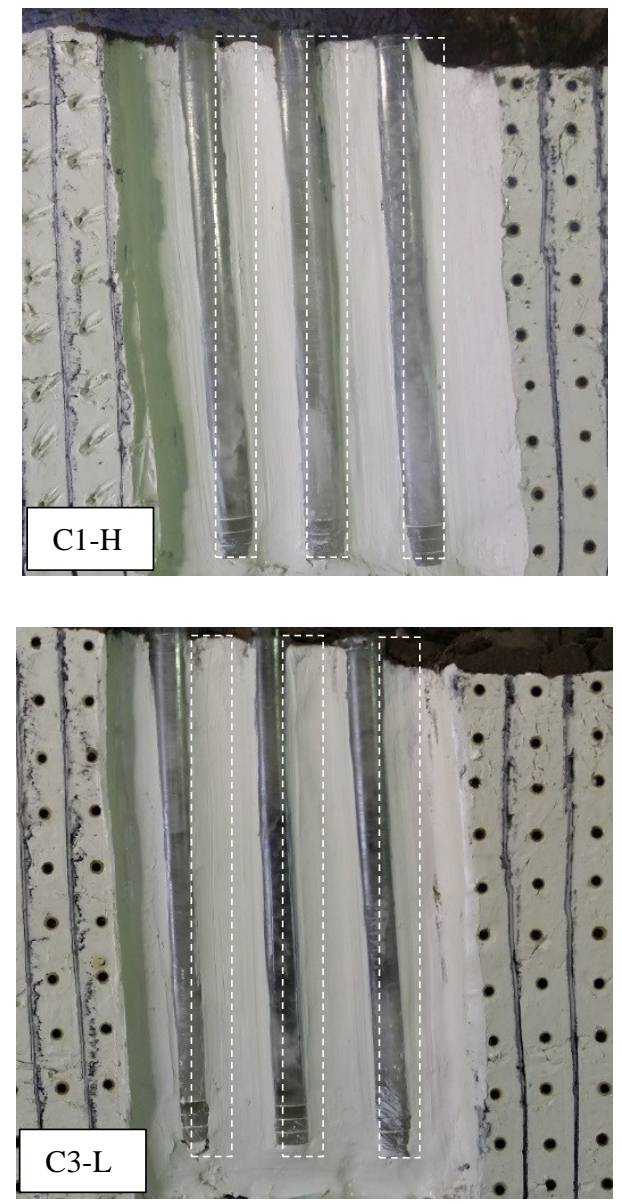

Fig. 11 Exposed columns after centrifuge tests window during loading and by excavating the surrounding clay after the centrifuge test for the final displacement. By comparing the PTV result with the measured displacement of the excavated columns, the reliability of using the optical markers for PTV technique was confirmed. In particular, as can be seen in Fig. 10 the final displacement of the columns obtained from two methods was plotted together with $\mathrm{C} 1-\mathrm{H}$ as a typical example. A good agreement between two methods with the same magnitude of columns' displacement confirmed the accuracy of using the PTV method.

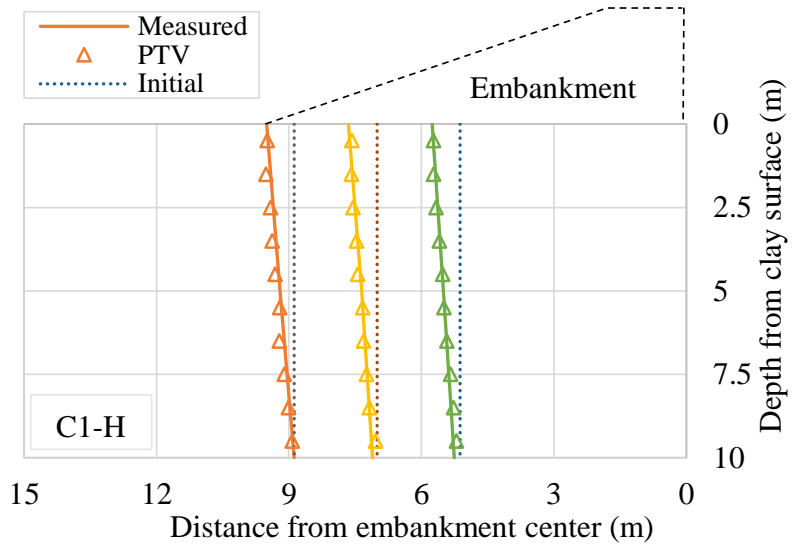

Fig. 10 Comparison of PTV and measured results $(\mathrm{C} 1-\mathrm{H})$.
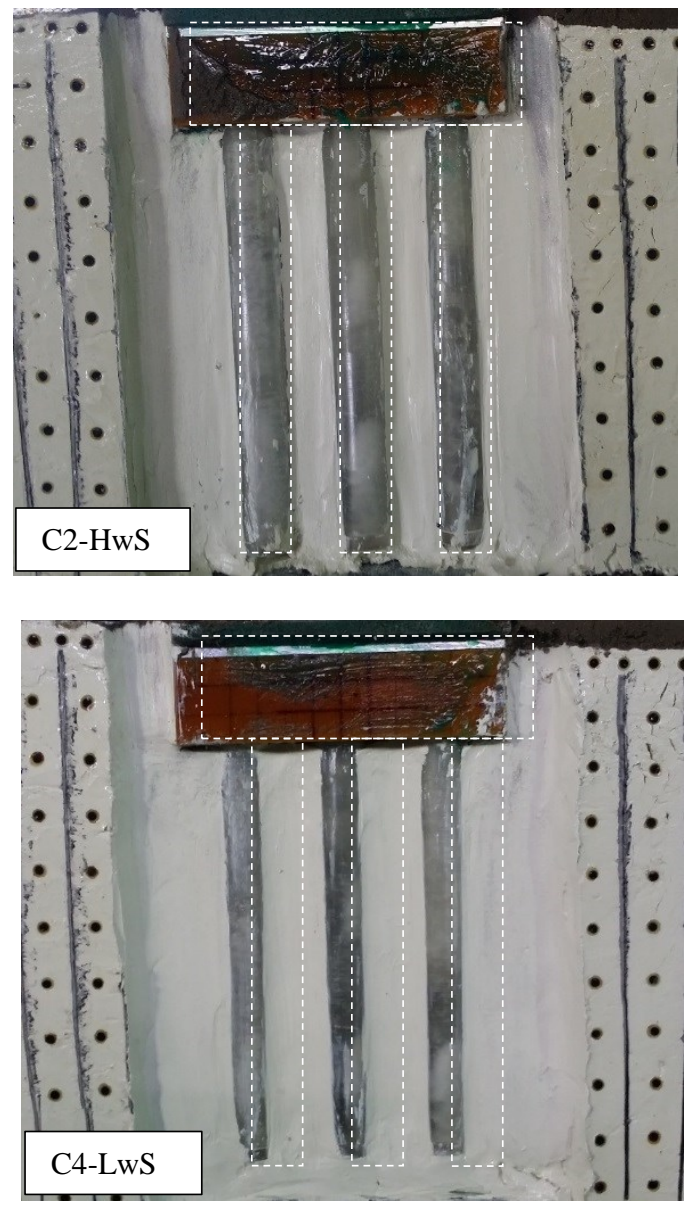

C4-LwS 
By observing the excavated columns in Fig. 11, the connection between the isolated columns and the shallow layer still remained rigid without any internal failure found in the columns as well as in the shallow layer at the final embankment pressure. Thus, the assumption of external stability of the columns and the rigid connection between the isolated columns and the shallow layer was guaranteed in the model tests. In the figure, the initial positions of the improved area are plotted by the broken lines for easy understanding of the movement of the improved area after the centrifuge tests. As can be seen from the figure, the isolated columns experienced a greater displacement at the top part in comparison to that reinforced by the stiff shallow layer. The same feature was found for both test condition with low- and high- strength bottom layer beneath the improved area.

In order to compare the displacement of these columns at the same embankment pressure, the displacement of the front columns at $150 \mathrm{kPa}$ of the embankment pressure observed by the PTV method is plotted together in Fig. 12. From the figure, the columns supported by high-strength bottom layer (C1-H and C2HwS) experienced a large tilting movement with small sliding despite the application of the shallow layer. By contrast, although the tilting movement is considerable in $\mathrm{C} 3-\mathrm{L}$, the sliding displacement significantly takes place when the columns rest on the low-strength layer, especially when the shallow layer is applied in C4-LwS. In the test without the shallow layer, the column in C3-L has the largest movement. When using the shallow layer, the tilting displacement is considered as the major displacement of the columns in $\mathrm{C} 2-\mathrm{HwS}$ while both the movement at the

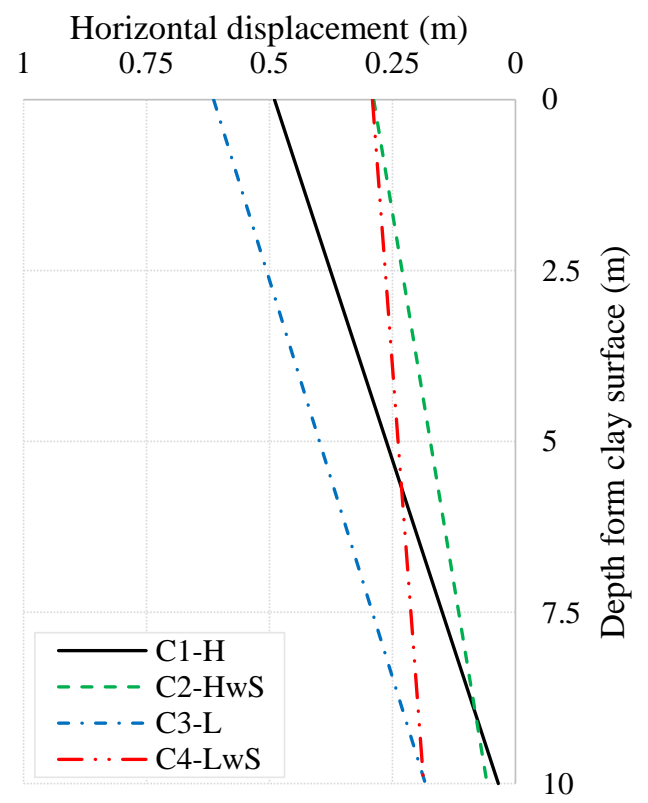

Fig. 12 Columns' displacement at $P_{\mathrm{e}}=150 \mathrm{kPa}$ of embankment pressure. top and bottom parts of the columns in C4-LwS are dominant for the floating type improvement. The failure pattern observed in this study well agrees with previous study that the tilting failure pattern was confirmed as the main failure mechanism of the isolated deep mixing columns in terms of external stability ${ }^{7)}$ especially with the columns resting on the highstrength bottom layer in $\mathrm{C} 1-\mathrm{H}$.

Due to a negligible vertical movement of the improved area, the displacement of the improved area can be divided into two components: the sliding and tilting displacements. Where the magnitude of the sliding displacement is obtained as the horizontal displacement at the columns' bottom, the tilting displacement is considered as the difference in horizontal displacement between the top and the bottom of the column. The tilting and sliding displacements are plotted against the embankment pressure in Fig. 13. By using the shallow layer in C2-HwS and C4-LwS, the tilting displacement significantly decreases regardless of the bottom layer strength (Fig. 13a). Furthermore, while the high strength bottom layer prevents the movement at the bottom of the columns, the columns experience greater tilting displacement which is mainly influenced by the movement at the column's top compared to that with the low-strength bottom layer regardless of using the shallow layer or not. By contrast, due to less resistance at the columns' bottom in C3-L and C4-LwS, the sliding displacement is much greater than that supported by the highstrength bottom layer, especially four times larger at $150 \mathrm{kPa}$ of embankment pressure (Fig. 13b). Irrespective of the shallow layer, the improved area supported by the low-strength bottom layer experiences almost the same magnitude in the sliding displacement.

For discussing the external failure mechanism of the improved area, two main factors including the shallow layer and the bottom layer's strength will be considered. First, the effect of the shallow layer is discussed in Fig. 14 where the proportion of the tilting displacement compared to total displacement was plotted against the embankment pressure. Particularly, the tilting displacement proportion decreases when the shallow layer is applied irrespective of the bottom strength condition as well as the embankment pressure. Detailed decrement in the magnitude of tilting displacement is clearly seen in Fig. 13. At 150 $\mathrm{kPa}$ of embankment pressure, the tilting displacement in the columns in $\mathrm{C} 1-\mathrm{H}$ and $\mathrm{C} 2-\mathrm{HwS}$ decreases to $50 \%$ when using the shallow layer, while that in the columns in C3-L and C3-LwS decreases to $100 \mathrm{~mm}$ from $450 \mathrm{~mm}$ (about $70 \%$ of decrement). The sliding displacement slightly increases in $\mathrm{C} 2-\mathrm{HwS}$ compared to $\mathrm{C} 1-\mathrm{H}$, while the shallow layer has negligible effect 


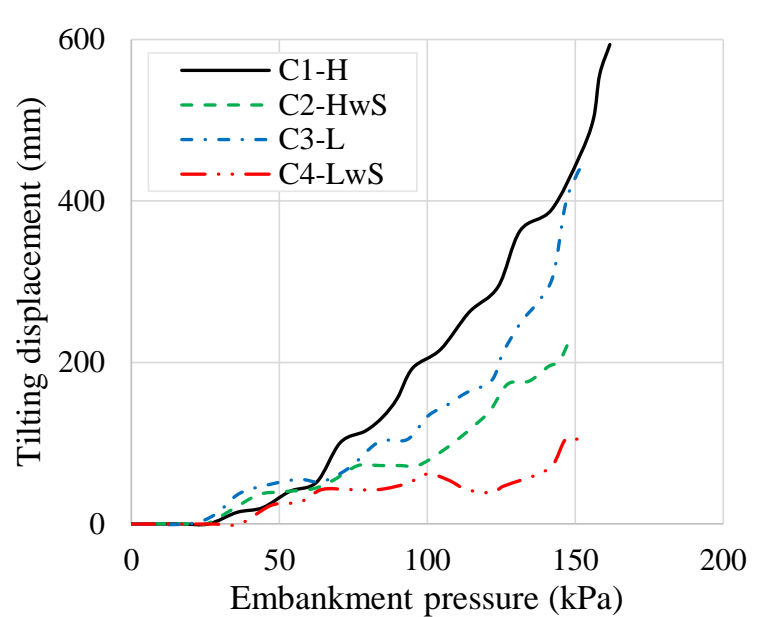

(a) Tilting displacement

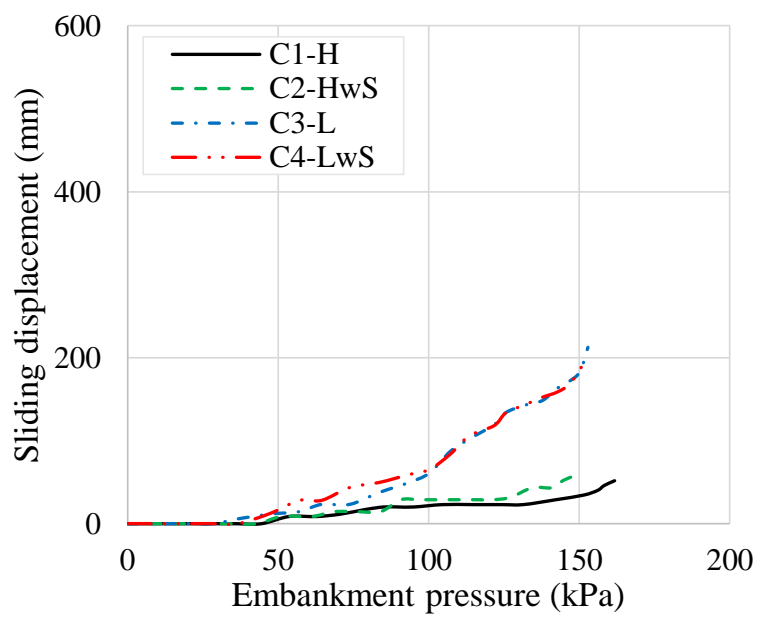

(b) Sliding displacement

Fig. 13 Displacements of improved area.

on the sliding displacement in the improved area resting on the low-strength bottom layer, which can be seen also in Fig. 13b. It can be said that the shallow layer has a considerable effect on reducing the tilting displacement of the isolated columns. However, the influence on the sliding displacement is negligible, irrespective of the bottom strength condition.

Second, the failure pattern of deep mixing column is also influenced by the bottom layer's strength. In Fig. 14, a smaller tilting proportion in total displacement can be seen in the columns with low-strength layer supporting the bottom than in the columns with high-strength bottom support regardless of using the shallow layer. On the one hand, the isolated columns experience almost the same amount of tilting displacement at $150 \mathrm{kPa}$ of embankment pressure, which can be seen in Fig. 12 and Fig. 13 (C1-H and C3-L). However, these figures also indicate that larger sliding displacement takes place in the improved area resting on the low-strength layer rather than that on the high-strength bottom layer. It means that the smaller ratio of tilting displacement in Fig. $\mathbf{1 4}$ is not caused by less tilting displacement but by a greater sliding displacement.

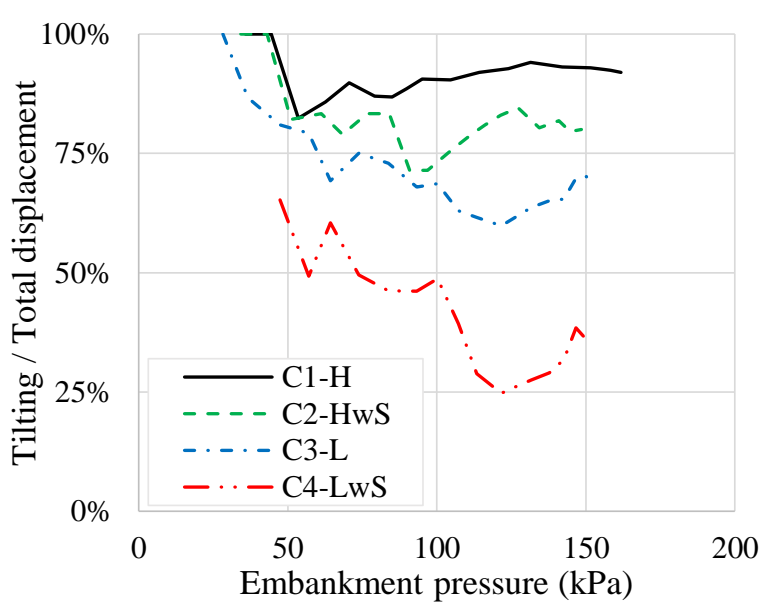

Fig. 14 Proportion of tilting displacement of improved area.

On the other hand, it can be seen in Fig. 12 that the total displacement of columns with a shallow layer is almost the same in both bottom strength condition beneath the improved area at the embankment pressure of $150 \mathrm{kPa}(\mathrm{C} 2-\mathrm{HwS}$ and $\mathrm{C} 4-\mathrm{LwS})$. Furthermore, Fig. 13 shows a greater tilting displacement as well as smaller sliding displacement in the improved area in C2-HwS than that in C4-LwS. That also can be used to explain the less tilting proportion in the total displacement as shown in Fig. 14 for the test with shallow layer. It is obvious that low-strength bottom layer may bring large sliding displacement of the improved area while high-strength layer prevents the sliding displacement regardless of using the shallow layer. As a summary for the centrifuge tests' results, the shallow layer functions to reduce the tilting displacement of the improved area while the sliding failure takes place easily when the bottom layer has low strength.

For discussion on the resistance mechanism of the proposed improvement method, the stability of the improved area is simply estimated by the equilibrium method using Rankin's theory. Three failure patterns that are mainly observed from the model tests are considered for evaluation including sliding failure, tilting failure of individual columns, and overturning failure of improved area as can be seen in Fig. 15. In particular, for the sliding failure pattern in Fig. 15a, the driving forces include active earth pressures from embankment and clay layer, while the passive earth pressure and the shear strength mobilizing from the bottom of the improved area are considered as the resistances. The safety factor for the sliding failure pattern is shown in Eq. (1) where the detailed components are presented from Eqs. (2) to (7).

$$
F_{\mathrm{s}}=\frac{P_{\mathrm{pc}}+F_{\mathrm{rf}}+F_{\mathrm{rc}}}{P_{\mathrm{ac}}+P_{\mathrm{ae}}}
$$




$$
\begin{gathered}
P_{\mathrm{ae}}=\gamma_{\mathrm{e}} \tan ^{2}\left(\frac{\pi}{4}-\frac{\phi_{\mathrm{e}}}{2}\right) \frac{H_{\mathrm{e}}^{2}}{2} \\
P_{\mathrm{ac}}=\left(\gamma_{\mathrm{e}} H_{\mathrm{e}}-2 c_{\mathrm{u}}\right) H_{\mathrm{c}}+\gamma_{\mathrm{c}} \frac{H_{\mathrm{c}}^{2}}{2} \\
P_{\mathrm{pc}}=\gamma_{\mathrm{c}} \frac{H_{\mathrm{c}}^{2}}{2}+2 c_{\mathrm{u}} H_{\mathrm{c}} \\
F_{\mathrm{rf}}=\left(\gamma_{\mathrm{col}} H_{\mathrm{col}}+\gamma_{\mathrm{e}} H_{\mathrm{e}} \frac{n}{1+(n-1) a_{\mathrm{s}}}\right) a_{\mathrm{s}} \tan \phi_{\mathrm{s}} W
\end{gathered}
$$

For high-strength bottom condition

$$
F_{\mathrm{rc}}=\left(1-a_{\mathrm{s}}\right) W c_{\mathrm{u}}
$$

For low-strength bottom condition

$$
F_{\mathrm{rc}}=W c_{\mathrm{u}}
$$

where:

$P_{\text {ae }}$ : total of active earth pressure of embankment $(\mathrm{kN} / \mathrm{m})$

$P_{\text {ac: }}$ : total of active earth pressure of clay $(\mathrm{kN} / \mathrm{m})$

$P_{\mathrm{pc}}$ : total of passive earth pressure of clay $(\mathrm{kN} / \mathrm{m})$

$F_{\text {rf: }}$ total of friction between columns and sand layer $(\mathrm{kN} / \mathrm{m})$

$F_{\text {rc }}: \quad$ total cohesive strength of clay $(\mathrm{kN} / \mathrm{m})$

$a_{\mathrm{s}}$ : improvement ratio

$B: \quad$ diameter of column (m)

$c_{\mathrm{u}}$ : $\quad$ shear strength of clay $(\mathrm{kPa})$

$H_{\mathrm{c}}$ : thickness of clay layer $(\mathrm{m})$

$H_{\text {coll }}$ : height of columns (m)

$H_{\mathrm{e}}$ : embankment height $(\mathrm{m})$

$H_{\mathrm{SL}}: \quad$ thickness of shallow layer (m)

$n: \quad$ stress concentration ratio

$N: \quad$ number of column lines

$S: \quad$ center to center spacing of columns (m)

$W: \quad$ width of improved area (m)

$W_{\mathrm{SL}}$ : width of shallow layer $(\mathrm{m})$

$\gamma_{\mathrm{c}}: \quad$ unit weight of clay $\left(\mathrm{kN} / \mathrm{m}^{3}\right)$

$\gamma_{\text {coll }}: \quad$ unit weight of column $\left(\mathrm{kN} / \mathrm{m}^{3}\right)$

$\gamma_{\mathrm{e}}: \quad$ unit weight of embankment $\left(\mathrm{kN} / \mathrm{m}^{3}\right)$

$\phi_{\mathrm{e}}: \quad$ friction angle of embankment (degree)

$\phi_{\mathrm{s}}: \quad$ friction angle of sand layer (degree)

Similarly, Fig. 15b shows a tilting failure pattern where the columns are assumed to collapse individually. The safety factor for the tilting failure pattern is presented in Eq. (8) with detailed moments described from Eqs. (9) to (15).

$$
F_{\mathrm{s}}=\frac{M_{\mathrm{pc}}+M_{\mathrm{rc}}+M_{\mathrm{sc}}+M_{\mathrm{re}}+M_{\mathrm{rt}}}{M_{\mathrm{ac}}+M_{\mathrm{ae}}}
$$

$$
\begin{gathered}
M_{\mathrm{ae}}=\gamma_{\mathrm{e}} H_{\mathrm{e}} \tan ^{2}\left(\frac{\pi}{4}-\frac{\phi_{\mathrm{e}}}{2}\right) \frac{H_{\mathrm{e}}^{2}+3 H_{\mathrm{e}} H_{\mathrm{c}}}{6} \\
M_{\mathrm{ac}}=H_{\mathrm{c}}^{2} \frac{3 \gamma_{\mathrm{e}} H_{\mathrm{e}}+\gamma_{\mathrm{c}} H_{\mathrm{c}}-6 c_{\mathrm{u}}}{6} \\
M_{\mathrm{pc}}=H_{\mathrm{c}}^{2} \frac{\gamma_{\mathrm{c}} H_{\mathrm{c}}-6 c_{\mathrm{u}}}{6} \\
M_{\mathrm{rc}}=\frac{\pi B^{2}}{4} \frac{N}{S} c_{\mathrm{u}} H_{\mathrm{c}} \\
M_{\mathrm{sc}}=S\left(1-a_{\mathrm{s}}\right)(N-1) c_{\mathrm{u}} H_{\mathrm{c}} \\
M_{\mathrm{re}}=\frac{\pi B^{3}}{8} \frac{N}{S} \gamma_{\mathrm{e}} H_{\mathrm{e}} \frac{n}{1+(n-1) a_{\mathrm{s}}} \\
M_{\mathrm{rt}}=\frac{\pi B^{3}}{8} \gamma_{\mathrm{col}} H_{\mathrm{col}} \frac{N}{S}
\end{gathered}
$$

where:

$M_{\mathrm{ae}}$ : moment by active earth pressure of embankment $(\mathrm{kN} \times \mathrm{m} / \mathrm{m})$

$M_{\mathrm{ac}}$ : moment by active earth pressure of clay $(\mathrm{kN} \times \mathrm{m} / \mathrm{m})$

$M_{\mathrm{pc}}$ : moment by passive earth pressure of clay $(\mathrm{kN} \times \mathrm{m} / \mathrm{m})$

$M_{\mathrm{rc}}$ : moment by adhesion mobilizing on the side of the column $(\mathrm{kN} \times \mathrm{m} / \mathrm{m})$

$M_{\text {sc }}$ : moment by shear strength of clay between the columns $(\mathrm{kN} \times \mathrm{m} / \mathrm{m})$

$M_{\mathrm{re}}$ : moment by weight of embankment on the column $(\mathrm{kN} \times \mathrm{m} / \mathrm{m})$

$M_{\mathrm{rt}}$ : moment by weight of the column $(\mathrm{kN} \times \mathrm{m} / \mathrm{m})$

Finally, overturning failure of the column group is assumed to take place as shown in Fig. 15c where the improved area tends to overturn as a block around its front toe with the safety factor of Eq. (16). When applying the shallow layer, the active and passive stresses were assumed to be the same as those in the case without the shallow layer. Only the failure pattern was assumed different from that of the isolated columns. The shear strength of the clay between the columns was not taken into account when the driving and resistant forces in this failure were almost the same as those in the collapse failure. While sharing the same active and passive earth pressure from embankment and clay layer with tilting pattern, other components are presented in Eqs. (17) to (19).

$$
\begin{gathered}
F_{\mathrm{s}}=\frac{M_{\mathrm{pc}}+M_{\mathrm{rc}}+M_{\mathrm{rt}}+M_{\mathrm{re}}}{M_{\mathrm{ac}}+M_{\mathrm{ae}}} \\
M_{\mathrm{rc}}=B^{2} c_{\mathrm{u}} H_{\mathrm{c}}
\end{gathered}
$$




$$
\begin{gathered}
M_{\mathrm{rt}}=\gamma_{\mathrm{c}}\left[\left(H_{\mathrm{c}}-H_{\mathrm{SL}}\right) W+W_{\mathrm{SL}} H_{\mathrm{SL}}\right] \frac{W}{2} \\
M_{\mathrm{re}}=\left(\frac{1}{2} \gamma_{\mathrm{e}} H_{\mathrm{e}} W_{\mathrm{SL}}\right) \frac{2}{3} W
\end{gathered}
$$

The calculation was done by using model ground's properties from the centrifuge experiments with the assumed stress concentration ratio ${ }^{7)}, n$ of 2 . Although the model grounds in centrifuge model tests were limited by the model box, the calculation was assumed to increase the improvement width as well as the embankment height to achieve the failure state of the model ground.

The embankment height at failure was investigated by setting the safety factor of 1 where details of the safety factor equation was used after Kitazume $(2006)^{7)}$. The critical embankment heights for all three assumed failure patterns were plotted together in Fig. 16 when increasing the improvement width. The results of the centrifuge model test were also plotted in the figure with $4.75 \mathrm{~m}$ of improvement width for high and low bottom strengths in Fig. 16a and $\mathbf{1 6 b}$, respectively. The improvement width is defined as the distance from the left side of most front column to the right side of the most rear column, which covers the area of columned improvement.
The embankment heights at failure in the centrifuge model tests were converted from the yield pressures shown in Fig. 9. As can be seen in Fig. 16a, the sliding failure pattern shows the greatest embankment height at failure compared to that with tilting and overturning failure when the improvement width is around $4.75 \mathrm{~m}$ for the high-strength bottom condition. Therefore, the sliding failure may not happen despite of the tilting or the overturning failure. The calculation result well agreed with the centrifuge model tests that the tilting failure took place as the main failure pattern for isolated columns $(\mathrm{C} 1-\mathrm{H})$. When applying the stiff shallow layer to connect the columns, the overturning failure mechanism was observed as the major failure pattern in the centrifuge model tests (C2-HwS). By turning to the result in Fig. 16b for low-strength bottom condition, all three assumed failure mechanisms show a similar critical embankment height with the improvement width of $4.75 \mathrm{~m}$. Owing to the same results obtained from centrifuge tests, the improved area failed under a combination of failure patterns. In particular, the sliding and tilting failure were clearly observed in the centrifuge tests for isolated columns in C3-L. The columns reinforced by the shallow layer experienced a sliding failure combined with an overturning one as shown in test case C4-LwS.

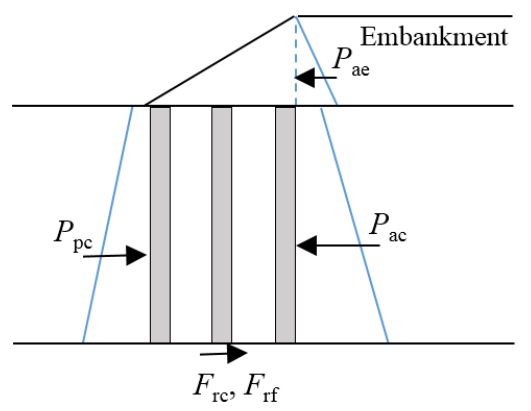

(a) Sliding failure

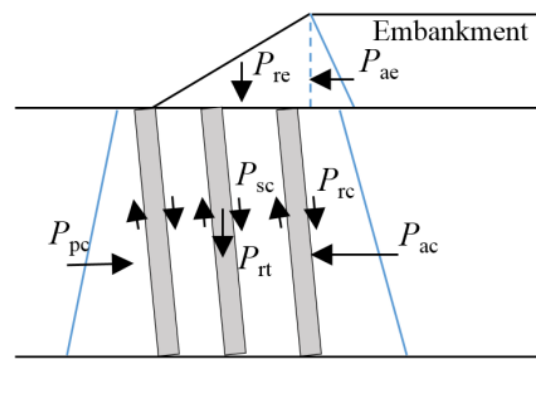

(b) Tilting failure

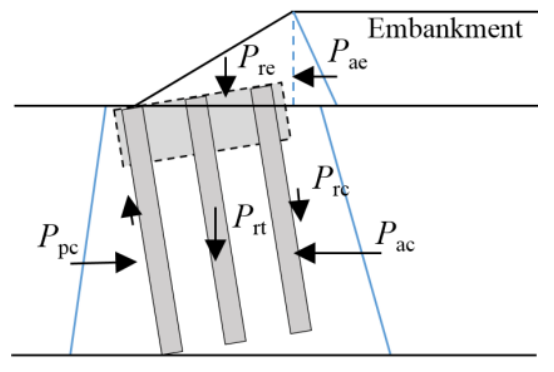

(c) Overturning failure

Fig. 15 Assumed failure mechanisms.

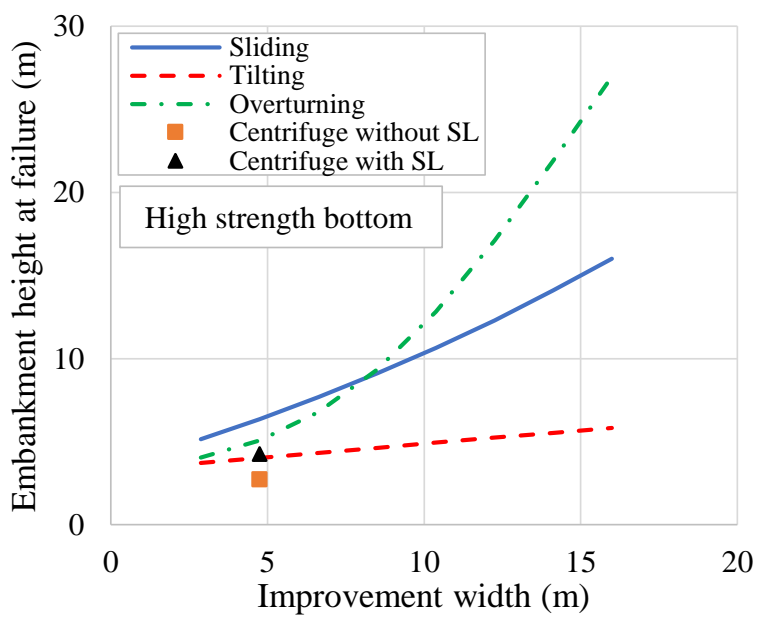

(a) High-strength bottom condition

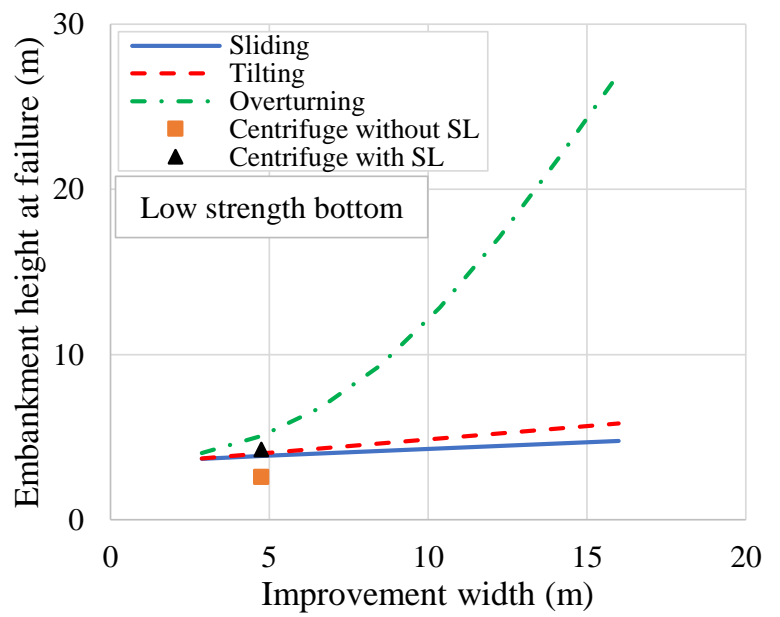

(b) Low-strength bottom condition

Fig. 16 Embankment height at failure with assumed failure mechanisms. 
The simple calculation was conducted with the assumption of full mobilization of all the forces listed in Eqs. (1) to (19), while the failure state was set suddenly when the safety factor equaled 1 . However, in the centrifuge tests, the failure pressure was assumed as the yield pressure where the failure of the model ground was about to start, while the mobilization of model ground may not fully take place at the defined failure pressure. These could be the reasons for the discrepancy on the embankment height at failure between the centrifuge model tests and the simple calculation. Although the slight difference was found in the embankment height at failure, the failure patterns observed in the centrifuge tests were confirmed by the simple calculation.

\section{SUMMARY AND CONCLUSIONS}

In summary, centrifuge model tests were successfully carried out to simulate the embankment constructing problem under 50 -gravity environment. The constructed embankment was supported by a group of isolated deep mixing columns located at the toe side of the embankment for the purpose of preventing sliding from the embankment slope. A shallow mixing layer was also used to reinforce the isolated columns. By comparing the test results between using the shallow layer reinforcement of the isolated columns and using only the isolated columns, the effect of the shallow layer is discussed in this study. Additionally, the influence of the strength of the bottom layer beneath the deep mixing columns is also considered. As a result, significant conclusions derived from this study in term of external stability are as follows:

- Tilting failure pattern is considered as the main failure pattern of the isolated column under the embankment pressure irrespective of the bottom strength condition.

- The shallow layer has strong effect on reducing the tilting failure pattern of the isolated columns but less influence on the sliding pattern regardless of the bottom layer's strength.

- While high strength of bottom layer prevents sliding displacement of improved ground, sliding failure easily takes place with low-strength bottom condition regardless of using the shallow layer or not.

- Using a shallow layer reinforcing the isolated columns results in higher stability of improved ground due to increase of about $50 \%$ of embankment pressure at yield, as well as decrease of at least $40 \%$ of embankment displacement in the conditions of this study.

\section{REFERENCES}

1) Kitazume, M. and Terashi, M.: The Deep Mixing Method, CRC Press, p. 410, 2013.

2) Terashi, M.: Theme lecture: Deep mixing method - Brief state of the art, Proc. 14th ICSMFE, Vol. 4, pp. 2475-2478, 1997.

3) Martel, D. W. and Piling, W.: Dam wall toe stabilisation using mass soil mixing techniques, Proc. of Deep mixing 2015, pp. 181-192, 2015.

4) Shrestha, R., Jose, S. and Griffin, R.: Deep mixing for levee repair at hurricane protection project, Proc. of Deep mixing 2015, pp. 257-266, 2015.

5) Bertoni, M. and Schmutzler, W.: Soil mixing for the LPV111 Levee improvement, New Orleans: A case history, Proc. of Deep mixing 2015, pp. 247-256, 2015.

6) Arnold, M.: Seepage cut-off wall installation using cutter soil mixing for Herbert Hoover dike rehabilitation, Proc. of Deep mixing 2015, pp. 213-222, 2015.

7) Kitazume, M. and Maruyama, K.: External stability of group column-type deep mixing improved ground under embankment loading, Soils and Foundations, Vol. 46, No. 3, pp. 323-340, 2006.

8) Kongsomboon, T. and Teperaksa, W.: Combination strength in analysis of soil cement column, International Conference on Soft Ground Engineering, Singapore, pp. 261-267, 2015.

9) Kitazume, M. and Maruyama, K.: Internal stability of group column-type deep mixing improved ground under embankment loading, Soils and Foundations, Vol. 47, No. 3, pp. 437-455, 2007.

10) Tatarniuk, C. and Bowman, E.: Case study of a road embankment failure mitigated using deep soil mixing, Grouting and Deep Mixing 2012, American Society of Civil Engineers, pp. 471-482, 2012.

11) Zheng, G., Diao, Y., Li, H. and Han, J.: Stability failure modes of rigid column-supported embankments, Geo-Congress 2013, American Society of Civil Engineers, pp. 18141817, 2013.

12) Ishikura, R., Ochiai, H. and Omine, K.: Evaluation of the settlement of in-situ improved ground using shallow stabilization and floating-type cement-treated columns, Doboku Gakkai Ronbunshuu C, Vol. 65, No. 3, pp. 745-755, 2009. (in Japanese)

13) Kitazume, M.: Effect of surface improvement layer on internal stability of group type deep mixing improved ground under embankment loading, Report of the Port and Airport Research Institute, Vol. 50, No. 1, 2011.

14) Chai, J. C., Hino, T., Kirekawa, T. and Miura, N.: Settlement prediction for soft ground improved by columns, Proceedings of the ICE - Ground Improvement, Vol. 163, No. 2, pp. 109-119, 2010.

15) Borges, R. and Almeida, M.: Centrifuge modelling of a buried pipeline below an embankment, International Journal of Physical Modelling in Geotechnics, Vol. 14, No. 4, pp. 116127,2014

16) Jiang, Z.: Model testing and numerical simulations of floating-type cement-treated columns during consolidation settlement, Proc. of 9th International Symposium on Lowland Technology, pp. 42-49, 2014.

17) Tsuji, T. and Kitazume, M.: Centrifuge model tests and numerical analyses on stability of soft clay slope improved by column-type deep mixing method, Master thesis at Tokyo Institute of Technology, 2013. (in Japanese)

18) Wang, C., Wang, B., Wang, X. and Zhou, S.: Centrifugal model tests on settlement controlling of piled embankment in high-speed railway, Traffic and Transportation Studies 2010, American Society of Civil Engineers, pp. 1407-1416, 2010 . 
19) Beasley, D. H. and James, R. G.: Use of a hopper to simulate embankment construction in a centrifuge model, Geotechnique, Vol. 26, No. 1, pp. 220-226, 1976.

20) Takemura, J., Kondoh, M. and Esaki, T.: Centrifuge model tests on double propped wall excavation in soft clay, Soils and Foundations, Vol. 39, No. 3, pp. 75-87, 1999.

21) Horii, N., Toyosawa, Y., Tamate, S. and Hashizume, H.: Centrifuge model test on the stability of a clayey ground improved by deep mixing method with a low improvement ratio, International Conferences on Recent Advances in Geotechnical Earthquake Engineering and Soil Dynamics, p.
19,2001

22) Davies, M. C. R. and Parry, R. H. G.: Centrifuge modelling of embankments on clay foundations, Soils and Foundations, Vol. 25, No. 4, pp. 19-36, 1985.

23) The Japan Society of Mechanical Engineer: Mechanical Handbook for Actual Use, 1990. (in Japanese)

24) Cowen, A. E. and Monismith, G. S.: A hybrid digital particle tracking velocimetry technique, Experiments in Fluids, Vol. 22, No. 3, pp. 199-211, 1997.

(Received September 14, 2015) 